\title{
Pedagogical translanguaging and the construction of science knowledge in a multilingual South African classroom: challenging monoglossic/post- colonial orthodoxies
}

\section{Margie Probyn}

To cite this article: Margie Probyn (2019) Pedagogical translanguaging and the construction of science knowledge in a multilingual South African classroom: challenging monoglossic/post-colonial orthodoxies, Classroom Discourse, 10:3-4, 216-236, DOI: 10.1080/19463014.2019.1628792

To link to this article: https://doi.org/10.1080/19463014.2019.1628792

\section{曲 Published online: 01 Oct 2019.}

Submit your article to this journal ๔

Џ Article views: 530

Q View related articles $\square$

View Crossmark data ¿`

Citing articles: 4 View citing articles 5 


\title{
Pedagogical translanguaging and the construction of science knowledge in a multilingual South African classroom: challenging monoglossic/post-colonial orthodoxies
}

\author{
Margie Probyn
}

Centre for Multilingualism and Diversities Research, Faculty of Arts, University of the Western Cape, Cape Town, South Africa

\begin{abstract}
The majority of learners in South African schools are African language speakers, yet the dominance of English in the political economy has meant that schools choose to switch to English medium instruction by Grade 4, before learners have the necessary English proficiency to access the curriculum, with negative effects on learning. This paper outlines South Africa's long engagement with such issues and documents the translanguaging practices of a teacher who breaks the post-colonial monolingual ideologies prevalent in classrooms and engages with learners' linguistic resources to provide access to both science knowledge and English.
\end{abstract}

\section{KEYWORDS}

Translanguaging; multilingual education; classroom discourse; science education; South Africa

South Africa's transition from colonialism and apartheid with the elections of 1994 was marked by widespread optimism in the power of the new democracy to transform society, including the system of education. A transformed education system based on the principles of equity, access and social justice was to be both a subject of and a key driver of social and economic change - as evident in the words of Nelson Mandela: 'The power of education extends beyond the development of skills we need for economic success. It can contribute to nation-building and reconciliation' (Mandela 1997). However, almost a quarter century into the democratic era, the historic imbalances and inequalities of apartheid education have been hard to shift, despite far-ranging policy changes. There remains a wide gap between the educational achievement of a minority of middle-class learners who attend well-resourced schools that were formerly reserved for white learners and some formerly Indian and 'coloured' schools; and the achievement of the majority of learners from working class and poor families who attend historically black township and rural schools and comprise $80 \%$ of the school-going population ${ }^{1}$ (Fleisch 2008; Van der Berg 2006). The need to close this achievement gap in education is widely perceived as critical for economic growth and social development and so is the subject of much research inquiry.

While the low socio-economic status of the majority of African language learners and the persistence of historic inequalities in material resourcing of township and rural schools clearly contribute to the achievement gap, a further contributing factor is that of language: learners in township and rural schools who speak indigenous African 
languages at home, switch to learning through the medium of English by the beginning of the fourth grade, irrespective of whether they have the English language skills necessary for effective learning. This switch to learning through the medium of a former colonial language, despite the apparently obvious negative impact on teaching and learning, is typical of many post-colonial countries (see Lin and Martin 2005; Rubagumya 1994) and appears to reflect the enduring influence of colonial ideologies and orthodoxies alongside the hegemony of English in a globalised world.

Thus in South Africa, and more generally in the global South, the challenges of multilingualism in education are a national rather than minority concern as in more often the case in the global North; and such concerns have a long history dating back to colonial times. This paper will provide a brief contextual overview of this research.

In South Africa, there is a long history of research into language alternation, in particular codeswitching, in multilingual classrooms. As Ferguson (2009) has suggested, there is a need to move beyond merely describing languaging practices in classrooms to examining how these impact on learning. This paper will present some findings from a small-scale case study that examined the languaging practices of a group of science teachers in multilingual classrooms, in relation to the opportunities for learning that their practices appeared to offer (or not); and how the heteroglossic pedagogical translanguaging of one teacher in particular seemed to offer greater opportunity to learn science than did the monoglossic and reactive code-switching of several of the other teachers.

\section{Language policies and practices in multilingual classrooms}

South Africa is by definition a multilingual country, and societal multilingualism is considered the norm. Eleven official languages are recognised in terms of the post-apartheid Constitution of 1996 (Republic of South Africa 1996): nine African languages as well as the colonial languages, Afrikaans and English, that were the two official languages prior to 1994. However, these constitutional provisions have not had the intended effect of promoting and expanding the relative power and status of previously marginalised African languages; and instead English continues to dominate the political economy, despite being the home language of less than $10 \%$ of the population (Statistics South Africa 2012).

Heugh (2014) (drawing on an analysis by Heine, 1977) has described the horizontal and vertical dimensions of multilingualism in post-colonial Africa: at community level people use local languages which form part of a language continuum across space, with permeable boundaries; and written standardised languages at this level represent fixed representations which are the result of missionary choices and accidents of location. This is contrasted with vertical dimensions of multilingualism according to which languages, including imposed colonial languages, are arranged in a hierarchy reflecting political power relations, and as such afford or restrict access to forms of political, social and economic power. These dimensions are clearly understood by those who feel excluded from arenas of power and so schools need to provide learners with access to both dimensions to unlock the opportunity to learn.

Language in education has been integral to the political history of South Africa: language has been used by those in power to divide and rule and by political activists, to resist and unify (for an historical perspective on language in education see for example, Hartshorne 1992; 
Heugh 2008). The linguistic profiles of schools today bear the imprint of apartheid: prior to 1990 and the demise of apartheid, the education system was segregated along the lines of race and language, with 19 different education departments and vastly unequal material provision and teacher training. One of the first initiatives of the new democratic government post-1994 was to establish a unified education system to address the challenges of access, equity, redress and social justice in education. Much has been achieved but the desegregation of schools has followed the lines of upward mobility with parents aspiring to send their children to better resourced schools that previously were reserved for English and Afrikaans speaking white pupils, as well as some historically Indian and 'coloured schools. As a result, these schools have become far more linguistically diverse. However, there has been very little desegregation in the reverse direction; and so the majority of African language learners remain in the most poorly resourced schools in townships ${ }^{2}$ and rural areas with little exposure to English outside the classroom. Class has largely replaced race as the determinant of educational opportunity (Soudien 2004).

In line with the language provisions in the 1996 Constitution, the Language-inEducation Policy (LiEP) (Department of Education RSA 1997) sought to promote multilingualism in education in order to redress the linguistic imbalances of the past and to promote national reconciliation after nearly four decades of the apartheid political system that was based on racial and linguistic segregation and oppression.

In terms of the LiEP learners must learn two languages as subjects, one of which must be the language of learning and teaching (LoLT); a more recent proviso is that all learners must learn an indigenous African language, as many schools were only offering English and Afrikaans (Incremental Introduction of African Languages) (Department of Basic Education 2013). The LiEP is less clear about the LoLT and despite advocating home language medium of instruction and school language policies that promote 'additive bilingualism', the decision-making on school language policy is devolved to the school governing bodies that are composed of parents and teachers. The way that the policy has played out in schools is that in formerly 'white', 'coloured' and Indian English medium schools the LoLT has mostly remained unchanged; and while learner bodies have become far more linguistically diverse, the linguistic profiles of teaching staff have changed little, so that assimilationist policies and what McKinney (2017) has described as 'Anglonormative' attitudes frequently prevail. Multilingualism is regarded as a problem rather than a resource and learners from other linguistic backgrounds and cultures are frequently positioned as deficient.

Many formerly 'white' and 'coloured' Afrikaans medium schools have had to introduce English medium streams to cater for Afrikaans speaking learners whose parents would like them to become proficient in English; and African language learners who for both political and pragmatic reasons do not want to learn through the medium of Afrikaans. As with the historically English medium schools, the linguistic profiles of teaching staff have remained relatively unchanged and teachers are frequently home language Afrikaans speakers who can communicate in English but not necessarily in African languages (see for example Fortuin 2017).

The result is that in these schools, home language speakers of English and a high proportion of Afrikaans speakers continue to learn through the medium of their home language throughout their schooling, whereas the African language learners are immersed in learning through an additional language and teachers are ill-prepared for 
engaging with the full range of linguistic resources that learners bring with them. The linguistic makeup of these schools has much in common with certain contexts in the global north where increasing mobility and migration have meant that many classrooms are becoming increasingly multilingual.

In historically 'black' schools, where the majority of learners speak an African language, rather than adopting policies supportive of 'additive bilingualism', with the learners' home language forming the basis for learning, the majority of schools have opted to switch to English medium instruction by the beginning of the fourth grade at the latest but frequently earlier. This is for a range of reasons but primarily the very real need to acquire English for upward mobility and economic access; and the common sense perception that time-ontask, i.e. learning through the medium of English, is the most effective way to achieve this, despite the fact that learners general have little access to English outside the classroom, and schools have poor resources to support English literacy. Thus, the medium of instruction frequently poses a devastating barrier to learning, what Macdonald (1990) has likened to 'swimming up a waterfall'. African teachers and learners often share a common home language and teachers are frequently in command of several African languages and so unlike their counterparts in historically 'white', Indian and 'coloured' schools, they are able to switch to the learners' home language to achieve a number of cognitive, affective and management goals (Ferguson 2009); but in line with language policy, assessment is in English.

This linguistic scenario is in common with many post-colonial countries and has been well researched and documented (for example Ferguson 2009; Lin 1996; Martin 1996; Rubagumya 1994). But it is a very different kind of context to that of the global north - although both are linked through the long history of European colonialism that shapes much of our current linguistic context; and is the subject of increasing critique and research in terms of policy and classroom practices (see for example Heugh 2014; Lin and Martin 2005; McKinney 2017).

\section{Translanguaging research in South African classrooms: current developments and historical precedents}

Along with the recent interest in translanguaging in multilingual classrooms in the global north, there has been a corresponding interest and research in translanguaging in South African classrooms, some of which documents spontaneous language use in classrooms (for example Krause and Prinsloo 2016; Probyn 2015) and some of which documents interventions that have adopted planned heteroglossic pedagogies that engage with learners' full linguistic repertoires (for example Guzula, McKinney, and Tyler 2016; Makalela 2015; McKinney 2017; Ngcobo et al. 2016)

The research on spontaneous language use in multilingual classrooms builds on a well-established body of research on code-switching in African language classrooms, stemming from concerns about the challenges of teaching through the medium of English where learners are not sufficiently proficient in English to be able to engage with learning. Carol Macdonald's (1990) seminal research in Grade 5 classrooms identified the gap between the English language proficiency of the Sepedi learners and the English language demands of the curriculum in Grade 5 when the switch to English medium instruction was made. She noted that teachers' classroom practices were moulded by the linguistic limitations of their students and so teachers and students frequently 
switched to their common mother tongue to communicate lesson content, and teachers resorted to writing up simplified notes on the chalkboard for students to copy and learn by rote, in order to cope with assessment in English (see also Adendorff 1996; Probyn 2001; Setati et al. 2002).

Much research on classroom codeswitching (Ferguson 2009) has come to the conclusion that codeswitching practices, although largely unplanned, are highly functional in supporting epistemic access, for classroom management and for affective purposes, including to reduce the tensions and alienation of learning through the medium of a strange language (Probyn 2001). However such practices do not have official sanction and so are regarded by teachers as a necessary evil, a deviation from a monolingual ideal and a source of conflict and tension (Probyn 2009; Setati et al. 2002).

The new enthusiasm for describing language alternation practices in classrooms as 'translanguaging' seems to call for a clarification of terminology. Some of what has recently been described as 'translanguaging' seems perhaps to be little different from what has hitherto might have been described as 'codeswitching'.

As is well known the term 'translanguaging' originated as a method of teaching where language input and output were alternated between English and Welsh, in order to develop bilingualism as well as associated cognitive benefits (Lewis, Jones, and Baker 2012). The notion of translanguaging has been adopted more recently by Creese and Blackledge (2010) Garcia (2009), Li (2017) and others as a counter to what has been termed a monoglossic orientation to bilingualism where languages are regarded as 'two solitudes' (Cummins 2008) to be kept separate in the classroom. The notion of translanguaging instead offers a heteroglossic approach, described by Baker (2011) as 'the process of making meaning, shaping experiences, understandings and knowledge through two languages. Both languages are used in an integrated and coherent way to organize and mediate mental processes in learning' ( $p$. 288). As Garcia and Flores (2012) note with reference to translanguaging:

These dynamic plurilingual pedagogies should not be confused with the random codeswitching that is sometimes prevalent in classrooms ... where language use is accidental and haphazard ... plurilingual heteroglossic pedagogies are done with intent and are carefully planned. (pp. 238-239)

The distinction between codeswitching and translanguaging in the classroom, therefore, is both ideological and pedagogical. The monoglossic orientation that gives rise to codeswitching as a deficit practice, originates at least in part with the colonial ideology of linguistic hierarchies, the superiority of colonial languages over indigenous languages; and notions of linguistic purity that parallel colonial notions of racial purity and superiority. Such attitudes are normalised over time and prove hard to shift even in the face of the very obvious learning difficulties that the majority of learners in township and rural schools face when immersed in learning through the medium a language they do not fully comprehend. By contrast, translanguaging practices offer alternate ways of viewing languages in the classrooms: as resources to be fully exploited in constructing knowledge so as to open up rather than constrain opportunities to learn.

Several South African research papers have documented innovative translanguaging interventions in and out of schools and in universities. These have historic precedents in early 'dual medium' initiatives in the 19th century when Dutch/Afrikaner pupils under British colonial rule were taught bilingually in English and Dutch, although the aim was 
political rather than educational, to assimilate Afrikaner children culturally and politically. In the first half of the 20th century, English and Afrikaans speaking (white) pupils were taught bilingually in the same class from Grade 7 (Heugh 1995; Plüddemann et al. 2004) in order to foster English-Afrikaans bilingualism and reconciliation between English and Afrikaans speaking whites in the wake of the Anglo-Boer War (1899-1902). Research on such dual medium programmes done in the 1940s (Malherbe, 1973, in Heugh 1995) provided some of the earliest evidence of the cognitive (and social) benefits of classroom bilingualism. It is not clear exactly whether or not there was a clear pedagogy associated with these early dual language classrooms, but it appears that teachers used languages flexibly and learners were allowed to use the language they preferred, including in assessment. Such schools fell out of favour under the Afrikaner Nationalist government from 1948 on but some continued to exist in small towns where there were not enough learners of both language groups in a school to warrant separate classes.

Heugh in 1995 proposed that dual medium instruction should be extended to all language speakers to achieve 'additive bilingualism'. She noted:

Flexibility is the key feature of the multilingual school. Teachers need to be flexible about when and how they alternate between two languages of learning. In some instances, it may even become necessary to alternate amongst three languages. Students should be able to choose their preferred language/s for the purpose of writing assignments and examinations in content subjects'. (p. 85)

These ideas were further developed by Neville Alexander and researchers at the Project for the Study of Alternative Education in South Africa (PRAESA) and presented as 'Mother-tongue-based bilingual education' (Alexander 2009), which was intended to achieve both the benefits of cognitive development in the home language and biliteracy in English.

In 2003 Ramani and Joseph (Ramani et al. 2007) introduced a dual medium undergraduate degree at the University of Limpopo where half the subjects were taught in English and half in Sepedi but where students drew on both languages freely in classroom discussions and worked with texts in both languages.

The above examples illustrate that in South Africa there has been a longstanding concern and involvement in multilingualism in education that in many ways foreshadowed the more recent concerns and initiatives in the global north.

More recent research in South Africa has described several small-scale interventions aimed at developing translanguaging pedagogies in various multilingual classroom contexts. Some examples are:

Makalela (2015) described two interventions, one addressing Grade 6 reading comprehension developed though English and Sepedi and the other involving the learning of Sepedi in a pre-service teacher education programme by students who had no prior proficiency in Sepedi. In the Grade 6 reading programme, the translanguaging intervention included bilingual vocabulary contrast; reading texts in one language with questions in the other language; development of oral reading skills in both languages; and development of learners' writing in both languages, including retelling stories in both languages. In both interventions, positive outcomes were recorded. 
Guzula, McKinney, and Tyler (2016) reported on two out of school programmes: an afterschool literacy club - Stars of Today Literacy Club - for Grade 3-6 learners in a Cape Town township; and a mathematics holiday camp for Grade 11 learners in the rural Eastern Cape. In the literacy club children were encouraged to exploit their full range of multilingual and multimodal meaning-making resources for games, story-telling and writing. In the mathematics holiday revision camp, the English-speaking teacher was supported by an isiXhosaspeaking learning facilitator, to open up the possibilities for multilingual engagement with learning mathematics.

Ngcobo et al. (2016) reported on an intervention to introduce isiZulu-English translanguaging approaches to summary writing in a university-based academic support programme for African language students. They found that students benefitted from the approach and tended to shuttle bi-directionally between languages, during the summary writing process.

Makalela (2015) makes an important point that multilingualism and working with several languages is very much in line with societal multilingualism and fluid heteroglossic practices in Africa - what he terms 'linguistic ubuntu' - drawing on the humanistic African term expressing the interdependence of persons: 'a person is only a person though other people' and applying it to heteroglossic languaging practices.

The above examples of translanguaging in multilingual learning spaces provide some starting points for opening up discussions about alternative practices that engage with and expand students' full linguistic repertoires, rather than shutting down what McKinney (2017, p. xv) has described as 'the most valuable resource a child brings to formal schooling'. Such practices open up opportunities for epistemic access, affirm learners' identities and cultures and challenge the prevalent monoglossic orthodoxies in classrooms.

In the light of the above discussion what follows is a more detailed examination of the classroom languaging practices of a particular science teacher who deliberately and systematically engaged with the full range of linguistic resources available to learners in jointly constructing science knowledge.

\section{Pedagogical translanguaging in a Grade 8 science classroom}

The data presented here is drawn from a small-scale multiple case study that set out to investigate classroom language and the teaching and learning of science in eight township and rural schools where the teachers and learners shared a common home language, isiXhosa and the LoLT was English. The starting point for the research was the poor performance of South African Grade 8 and 9 learners in international science assessments such as TIMSS where they have consistently achieved the lowest scores of all participating countries. Successive TIMSS reports have identified the language medium of the tests where it was not the home language of learners, as a contributing factor to their poor performance but noted too that this factor co-occurs with other factors such as poverty and historically disadvantaged schools and so is difficult to disentangle (Howie 2001; Prinsloo and Rogers 2013; Reddy 2006).

This research study therefore set out to examine the role of language in teaching and learning science in a sample of Grade 8 science classes, where the home language of the learners and teachers was isiXhosa, and the language of learning and teaching was English; and extent to which classrooms languaging practices appeared to construct or constrain the opportunity to learn science. 


\section{Conceptual framework}

The framing concept for this research study was that of 'opportunity to learn' (OTL) which holds that 'students can only be accountable for their academic performance to the extent that the community, broadly defined, has offered them the tools to master the content expected of them' (McDonnell 1995, 312). In the light of this, and the poor performance of South African learners in the TIMSS assessments, the main research question was: What is the nature of the science content and the classroom language practices that support learners' opportunity to learn science in multilingual classrooms?

In order to answer the research question, both the science content of lessons and the language used to construct that content, were considered.

Key ideas about classroom science that informed the research are briefly outlined as follows:

- Science knowledge is empirically based and structured hierarchically, with increasing generalisation and explanatory power (Bernstein 2000).

- According to Donovan and Bransford (2005), an important aspect of learning science with meaning is coherence: science facts are linked to generalised conceptual frameworks; and conceptual frameworks are supported by rich factual detail.

- Learning science involves also learning the particular discourse of science, including the specialised terminology, discourse structures and genres typical of science texts (Gibbons 2006; Lemke 1990; Martin 1990; Mortimer and Scott 2003).

- Science lessons generally follow an explanatory arc of observation $\leq$ description $\leq$ explanation s generalisation (Gibbons 2006; Mortimer and Scott 2003).

The study of classroom language practices was viewed through two lenses, those of the classroom discourse, drawing on socio-cultural perspectives of the construction of knowledge and the literature on bi-/multilingual education. Although these perspectives are not ordinarily combined in research, the study aimed to examine how they might work together to construct or constrain opportunities to learn science.

The analysis of the classroom discourse drew on the work of Barnes $(1976,1992)$ who has drawn attention to the importance of pupils' talk in learning and the distinction between 'exploratory talk' when the focus is on learners sorting out their ideas; and presentational talk when they offer a 'final draft' for display and evaluation. The analysis took account of the social construction of knowledge through classroom talk (Mercer 1995) and how a teacher may expand the IRE classroom interaction patterns that tend to dominate classroom talk (Mehan 1979 ) by modifying the evaluation move $(E)$ to that of feedback, so as to build on learners' responses and engage with their ideas in a 'genuine dialogic co-construction of meaning' (Wells 1999, 86).

Alexander's more recent work on dialogic teaching (Alexander 2006) has prompted a reappraisal of whole class dialogue that 'chains ideas into coherent lines of thinking', enabling teachers to engage learners in linking of facts and observations through argument into conceptual frameworks in what amounts to reasoning aloud - a critical aspect of developing content coherence. Mortimer and Scott (2003) have developed these ideas in the context of science teaching and learning and make the important point that simplistic dichotomies between teacher-centred and learner-centred approaches are not helpful but 
that teachers need to develop a range of discourse repertoires; and that in science lessons for example, different patterns of classroom discourse and interaction function for different purposes at different points in a lesson - and the key question is whether interaction patterns in the discourse are appropriate for the stage and learning purpose in a lesson. The range of discourse interactions patterns for the analysis were adapted from the work of Gibbons (2006). An additional interaction pattern inserted in the analysis is that of 'oral cloze' (Cath \& McLellan, 1993 cited in Martin 1996) that is common in post-colonial contexts. The discourse interaction patterns are briefly outlined below on a continuum from least to most learner engagement:

- teacher monologue where the teacher does not seek verbal responses from students;

- 'oral cloze' where teacher asked a question and cues the response, usually with a rising tone;

- IRF (Initiation-response-feedback) where the teacher seeks one word or brief answers from students;

- dialogic exchanges where IRF exchanges are chained into semantically linked sequences and depend on the contingent responses of the teacher;

- participatory exchanges where the agenda is shaped by all participants - mainly in group work.

Research by Gibbons (2006) has also shown how good teachers orchestrate a 'bridging discourse' in order to support learners as they move along the oral to written mode continuum: from face-to-face, context-embedded talk around practical activities, that utilises everyday knowledge and language - what Bernstein has referred to as horizontal discourse - to using more abstract, context-reduced, generalised, scientific knowledge and language - Bernstein's vertical discourse (Bernstein 2000).

As already described, in multilingual South African classrooms, many teachers utilise the learners' home language/s as a bridge to understanding the lesson content in English. Setati et al. (2002) have described this 'journey' from informal exploratory talk in the learners' home language to formal written science discourse in English, as following a range of possible paths. This is closely echoed by Lin $(2012,93)$ in the multilingual context of Hong Kong, where she refers to the notion of 'bridging resources' in multilingual classrooms and different possible pathways from L1 everyday oral language to L2 academic written language. Ferguson (2009) identified the possible purposes for language alternation in multilingual classrooms as: to communicate knowledge, for classroom management and for affective purposes. Ferguson also advocated moving beyond simply identifying surface patterns of language alternation to a consideration of how such practices might impact on learning. In this regard the work of Cummins (1980) is helpful, in particular, his theories on language and cognition and the interdependence of languages in the brain; and his advocacy of 'teaching for transfer' (Cummins 2008) across languages that aligns with current work on translanguaging for epistemic access.

\section{Research context}

The Eastern Cape, where this research study was conducted, is one of the most rural and poor provinces in South Africa: statistics for 2012 showed that over 30\% of the 
population was illiterate; $42 \%$ of the population was unemployed; and $47 \%$ of the population was living in poverty (Kane-Berman and Holborn 2012).

School infrastructure in the Eastern Cape bears witness to the legacy of apartheid and in 2011 of the 5,676 schools in the Eastern Cape, 10\% had no toilets and only $17 \%$ had flush toilets - the rest would be pit latrines; $19 \%$ of schools had no water and $20 \%$ had no electricity; only $3 \%$ of schools had stocked libraries and $2 \%$ had stocked laboratories. In 2013 there were still over 400 mud schools $^{3}$ in the province (John 2013).

The linguistic context of Eastern Cape is that the majority of teachers and learners share a common home language, isiXhosa, while the official language of learning, teaching and assessment is English from Grade 4. However, few learners achieve the necessary academic skills in English in order to successfully access the curriculum as there are few opportunities to acquire English outside the classroom; the predominance of isiXhosa in communities means that there is very little interaction with English speakers and there are limited written resources in communities and schools to support literacy development in either isiXhosa or English.

Unsurprisingly, the Eastern Cape has one of the lowest records of academic achievement in national and international assessments and so the need to for research to explore ways of addressing some of the underlying challenges is particularly urgent.

Three of the schools in the study were located in townships on the outskirts of the city of East London; and five schools were located in remote rural villages.

\section{Data collection and analysis}

The primary data collected were videotapes of a series of five consecutive science lessons for each of eight science teachers. This was so as to be able to track the science content of the lessons as this unfolded over time, as classroom discourse analysis has been criticised for attending to surface features of language and not paying sufficient attention to meaning (Christie 2002; Gibbons 2006). The videotaped lessons were transcribed and analysed using socio-cultural discourse analysis (Mercer 2004) so as to take account of both the science content of lessons as well as the language used to construct that knowledge; and the extent to which classroom practices appeared to construct or constrain opportunities to learn science. The classroom language in the transcribed lessons was disaggregated into the classroom discourse interaction patterns, and the bilingual languaging practices of teachers and learners. In addition, teachers were interviewed to ascertain their views on the role of language in learning science and to reflect on the lessons that has been videotaped.

\section{Research findings}

It appeared from the analysis of the data that the opportunity to learn science was markedly greater in the practice of one teacher (Teacher B).

What was immediately evident in the analysis of the data was that Teacher B used far more isiXhosa than did the other teachers: $53 \%$ of the teacher talk in his lesson was in isiXhosa versus between $0 \%$ and $13 \%$ for the other seven teachers. What was also apparent in the reflective interviews with the teachers that Teacher B's orientation towards multilingualism was heteroglossic in that he regarded the learners' home language as an 
important resource for meaning-making. He claimed in his interview that his approach was to first build understanding in the learners' home language and then transfer that understanding to English. This was evident in his practice: when the focus of the lesson was on working on meaning - exploratory talk - Teacher B used more isiXhosa than English; and when learners were required to review ideas or in the consolidation phase of a lesson presentational talk - then Teacher B used more English than isiXhosa and required learners to do the same. This deliberate and systematic use of both languages to mediate learning is in line with Cummins' notion of 'teaching for transfer' (Cummins 2008) and the literature on translanguaging as outlined earlier. In addition, Teacher $B^{\prime} s$ translanguaging practices appeared flexible and responsive to learners' needs: at times he would elicit a concept in isiXhosa and then get learners to express it in English; or when a learner was struggling to express herself in English, he told her to speak isiXhosa.

By contrast, the five teachers who used isiXhosa for between 3\% and 13\% of their classroom talk, displayed a monoglossic orientation to the language resources in the classroom in that they felt compelled to stick to teaching in English and were conflicted about resorting to switching to the learners' home language when they observed from the learners' expressions that they were not following the lesson content.

Teacher C: When I look at them I can see that some of them don't understand ... I can see if they are uncomfortable, from their faces and I can see ... mmm ... they don't understand so I must repeat this in their mother tongue.

However, this raises the question as to whether this relatively brief and reactive codeswitching would in fact support learners' opportunity to systematically build their science knowledge; or if it might only provide them with relatively patchy comprehension and leave them with critical gaps in their science knowledge.

While Teacher B's pedagogical translanguaging contributed to a greater opportunity to learn science for learners in his class, it appeared to be a necessary but not sufficient condition. As described earlier the analysis of the teachers' practices included analysis of the science content in the lessons, in particular, the coherence of the content which has been identified as an important condition for learning science with understanding (Donovan and Bransford 2005). In this respect, the practice of Teacher B stood out from the rest in that the science content of his lessons was systematically linked, through argument, to key generalisations and conceptual frameworks. This appeared to be a key strength in the practice of Teacher B and correspondingly, a shortcoming in providing opportunities to learn science in the lessons of the other seven teachers when learners were left with a fragmented collection of facts rather than clear hierarchically structured science concepts.

The third aspect of the opportunity to learn science that was considered in the analysis was that of the classroom discourse interaction patterns and evidence of 'bridging discourses' drawing on the work of Gibbons (2006). As argued, it would seem that what has been described as dialogic discourse is important for engaging learners in extended exchanges and for modelling the arguments that link facts into generalisable conceptual frameworks, thus establishing content coherence and the opportunity to learn science with understanding. An analysis of the discourse interaction patterns showed that in the case of Teacher $B$, the science content was developed mainly through dialogic exchanges, which contributed to the coherence of the science content in his lessons. Conversely, the lack of sustained dialogic exchanges in the other seven classes contributed to the fragmented nature and lack of 
coherence of the science knowledge in those classes and so constrained the learners' opportunities to learn science. In addition, Teacher B systematically enacted a bridging discourse between everyday knowledge and language and scientific knowledge and language; and between exploratory talk, presentational talk and writing, across the mode continuum.

\section{Examples of practice}

Annotated extracts from one of Teacher B's lessons, are presented to illustrate the above points. The lesson on separating a mixture of soil and water was one of a series of lessons on mixtures and compounds. The lesson unfolded through the following stages in an explanatory arc of practical work $=>$ observation $=>$ description $=>$ explanation $=>$ generalisation $=>$ application $=>$ writing. There were 37 learners (in the class, 24 girls and 13 boys) seated in seven groups.

- Stage 1: Review

- Teacher B reviewed the key ideas from the previous lesson and elicited the key principle relevant to the separation of mixtures: the method of separation was dependant on the difference in properties between the substances in the mixture. He told the class that they would be separating a mixture of soil and water.

- Stage 2: Setting up practical activity

- Teacher B set up the practical activity, organising the groups, and handing out equipment/apparatus (a glass jar, a funnel and filter paper).

- Stage 3: Demonstration by learner

- A learner was called up to demonstrate how to fold the filter paper to insert it into the funnel and to explain what she was doing as she folded it.

- Stage 4: Conducting group practical activity

- Teacher B handed out soil and water to each group and told them to mix this in a bowl and then pour the mixture into the funnel to filter it into the glass jar.

- He asked probing questions while he walked round the class monitoring the activity.

- Stage 5: Reporting back observations

- Teacher B elicited observations from the learners and led them through an explanation of the observations and then a generalisation about the key principle for separating mixtures.

- Stage 6: Group discussion - application to everyday experience

- Learners had to discuss when they would use the filtration method to separate a mixture at home.

- Stage 7: Reporting back

- Learners reported back on examples of filtration at home.

- Stage 8: Writing

- Learners had to individually draw and label the experiment.

Below are illustrative excerpts from the different stages of the lesson.

' $T$ ' stands for 'teacher; ' $L$ ' for 'learner; 'Ls for 'learners' and 'SL' for 'same learner' - to indicate that a learner continued to respond through more than one turn. The isiXhosa is written in italics and the translation given in square brackets. Known 
English words are frequently 'Xhosalised' (Probyn 2001) - that is given an isiXhosa prefix ' $i-$ ' (singular) or 'zi-' (plural).

Excerpt 1: In Stage 1, the review of existing knowledge, Teacher B established the key principle for separating mixtures, namely that the method of separation depended on the difference in properties of the substances in the mixture. This was necessary for establishing coherence within and across the series of lessons on separating mixtures (Donovan and Bransford 2005) and was to provide the conceptual framework for the practical activity that followed. Teacher B used a brisk IRE sequence and spoke mainly in English as this was a review of known science content knowledge.

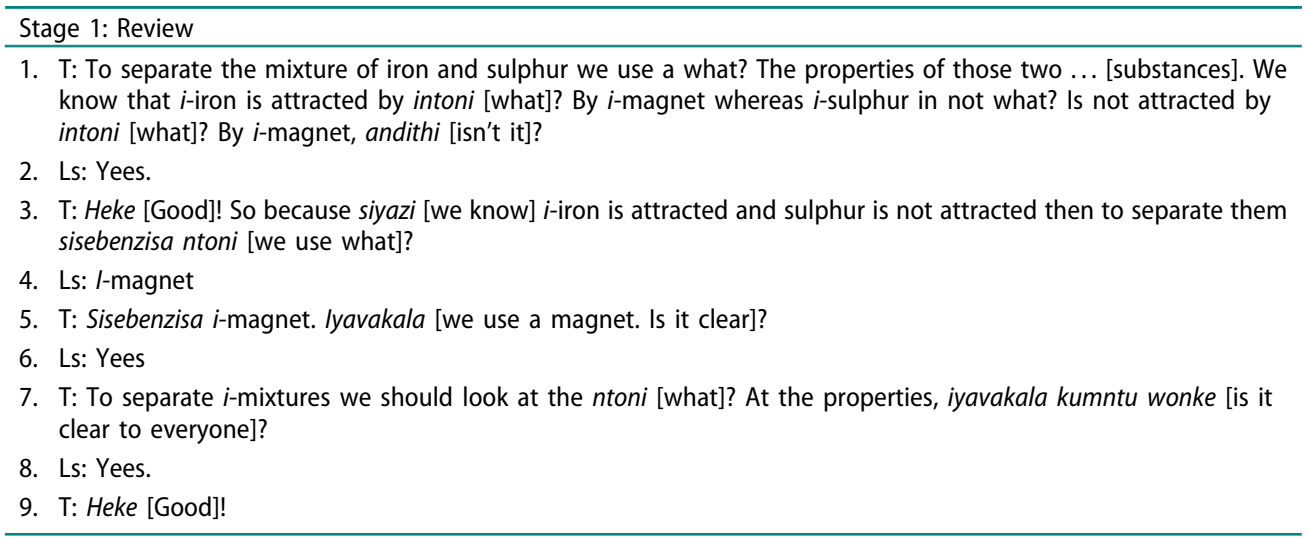

Excerpt 2: In Stage 2, setting up the practical activity, Teacher B handed out the practical apparatus, elicited the correct terms for the apparatus and wrote up the words on the chalkboard. He taught the meaning of the scientific word 'apparatus,' first eliciting the everyday meaning in isiXhosa and then transferring that to English.

Stage 2: Setting up practical activity

1. T: Neziya sizibiza intok'ba ziapparatus, apparatus zizinto ezitheni eziya, apparatus zizinto eztheni eziya [and those things we call apparatus, what are those things, what are those things for]? Zizinto ezitheni [what are those things for]? Mhmm? Xa sithethat nge apparatus sizakuthi zizinto ezitheni [when we talk of apparatus what can we say about them]?

2. Ls: Esizisebenzisayo [things we use].

3. T: Heh?

4. Ls: Zizinto esizisebenzisayo [they are things we use].

5. T: Heke [good]. Things that we use, instruments we use when conducting experiments sawzbiza uba zintoni [what can we call them]? Zi-apparatus, ne [they are apparatus, right]?

6. Ls: Yees

Excerpt 3: In Stage 3, a learner was asked to demonstrate and explain how to fold a filter paper to fit in a funnel. Teacher B led her through the explanation, first in isiXhosa and then in English. Teacher B's responses were tightly tied to those of the learner as he scaffolded her sustained explanation and demonstration. 
Stage 3: Demonstrating and explaining how to fold a filter paper

1. T: Makasixelele abemnye intok'be wenze kanjani, asidemonstrathele [one should tell us how they did it, demonstrate for us]. (indicating a learner in the front of the class) Yenza ntombazana esekuqaleni [show us girl at the front]. Yikhuphe [take it out], take it out usidemomnstrathele ukuba uyenza kanjani [demonstrate as to how you did it].

2. L: Ndisonge iphepha eli [I folded the paper].

3. T: Mhmm? Xela uba ulisonge kanjani sicimele ngoku [describe to us how you folded paper, imagine we had our eyes closed].

4. SL: Ndilisonge phakathi, tishara [I folded it in half, teacher].

5. T: Demonstreytha sibonise [demonstrate, show us]

6. SL: Ndithe njengoba linjena.nje ndalisonga phakathi [I just folded it in half]

7. T: You fold it in what? Xa uligoba phakathi yintoni lendawo uligoba kuyo [when you fold it in half what is the name of the part where you fold it]? Heh? In what?

8. SL: Centre

9. T: I-centre [The centre]?

10. SL: Half

11. T: Half? So you fold it in what?

12. Ls \& $\mathrm{T}:$ In half,

13. T: Heke qhubeka ke [good, go on then].

14. SL: Ndaphinda ndaligoba, tishala [I folded it again teacher].

15. T: In what?

16. SL: In half

17. T: Heke. Wenza iikota, ne [Good. You made quarters, right]? So you fold it in half. So xa usenza i-half [when you make a half] you make $i$-half of this half, ne [okay]?

18. Ls: Yees

19. T: Heke [good]. Kanjeya [like that]. Then kwathini ke ngoku [what happened]?

20. L: Ogqiba ndalivula ngaphakathi tishara [after that I opened the inside, teacher]

21. T: Heke [good]. Then you ... you ... you what?

22. Ls: You open

23. T: Heke [good]. Kanjeya nantsiya ifanele yakho [Like that there is your funnel] and you fit it in, you fit it in. Nantsiya [There it is].

Excerpt 4: In Stage 4 of the lesson, during the group practical activity when the learners were filtering the mixture of soil and water, Teacher B walked round the class, monitoring the activity and asking probing questions. In this episode of exploratory talk, while learners were working on meaning, the teacher and learners talked about the experiment, mainly in isiXhosa.

Stage 4: Group practical activity

1. T: Ikhona into esiyibona isenzeka [do we see anything happening], mhmm? Phaya ikhona into eyenzekayo [is there anything happening there]? Xa uyibambayo le nto [when you hold this thing] you hold it apha bambela apha ukwenzela sizokwazi ukubona yonk'into [here so that we can see everything]. Bambela apha [hold it here]. So ikhona into esiyibona isenzeka [so do we see anything happening]?

2. Ls: Yees.

3. T: Mhmm? So apha kuni [there with you] anything? Apha kuni [how about you]. Kwenzeka ntoni [what is happening]? What's happening apho kuni [there with you]?

4. L: Ahluzekile, tishara [it is filtered, teacher]

5. T: Ahluzekile [it is filtered]?

6. SL: Yes

7. T: Apho kuni [how about you]? Let's go ... let's look at that group. Phakamisani eyenu into sibone [raise your one so we can see].

8. L: Akahluzekanga tishala [it is not filtered, teacher]

9. T: Aphume esemdaka apho kuni [did it come out still dirty with you]?

10. Ls: Yes

11. T: Inokuba kwenzeke ntoni [what could have happened]? 
Excerpt 5: Reporting back. Teacher B led the learners through the process of describing what they had observed and then elicited an explanation as to why it had happened. The interactions followed a dialogic interaction pattern and the explanation was first developed in isiXhosa and then transferred to English.

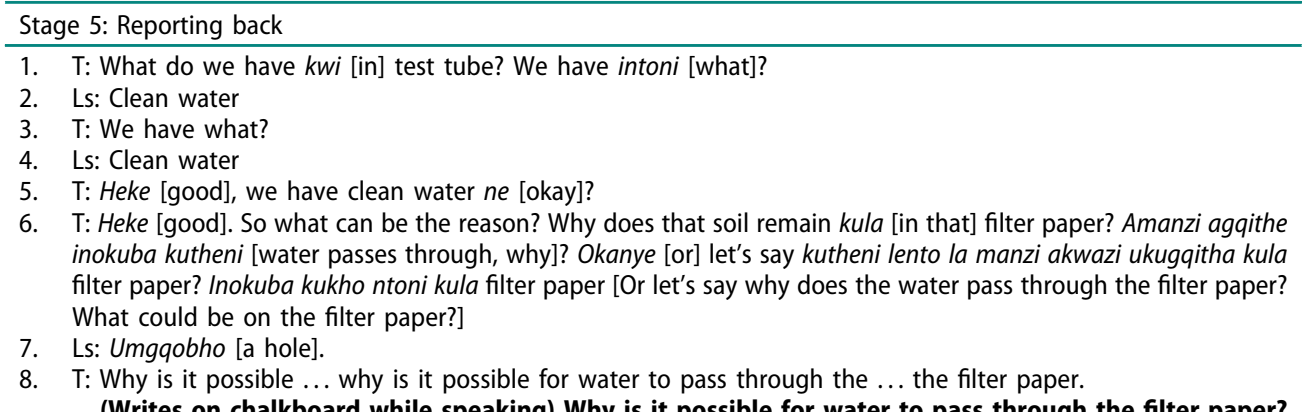

(Writes on chalkboard while speaking) Why is it possible for water to pass through the filter paper? Sithe inokuba kukho ntoni kula filter paper [what did we say could be on that filter paper]?

9. Ls: Umgqobho [a hole]

10. T: Umgaobho. Yintoni umgqobho ngeslungu [A hole. What is a hole in English\}?

11. L: Hole

12. T: Heh?

13. SL: Hole

14. T: Holes heke [good]. So it shows us that the there are some holes ... there are some holes in the filter paper there are some holes in the filter paper. Now xa zikhona ezaholes [if there are holes] why does soil not pass through the holes together with amanzi [water]? Mhmm? Phakamisa isandla [put up your hands]. Why does soil not pass through, why does soil not pass through the filter paper? Masithi phaya [let us say there] filter paper has what? Sithe [we said] i-filter paper has intoni [what]?

15. Ls: Holes.

16. T: Heke [Good]. Holes, heh? Then uthi umbuzo olandelayo [the following question] why does soil not pass through the filter paper together with intoni [what]? Amanzi [water]. (writing on the chalkboard)

Filter paper has holes. Why does soil not pass through the filter paper together with water Why does soil not pass through the filter paper together with water? Kutheni[Why]? Hands up. (nominates learner)

17. L: Inomgqobho omncinci [has small hole]

18. T: Mhmm?

19. SL: Inomgqobbho omncinci, tishara [has a small hole, teacher]

20. T: Intoni [what]?

21. SL: I-filter paper

22. T: So i-filter paper inomgqobho omncinci. Ngesilungu uzakuthini? Masimncediseni uba athethe lanto ngesilungu [has a small hole. In English how can we say that? Let's help her say that in English]? Ngubani oza kuzama [who can try]? Ozakuzama khawtsho (nominates learner) [who can try to speak]?

23. L: Filter paper has small holes.

24. T: Filter paper has small holes, ne [right]? So we say $i . i \ldots i$-soil does not pass through. So we say $i$-soil does not pass through i.i.-i-filter paper kuba kaloku [because remember] i-holes ze.zefilter paper zinjani [are what]? They're small ne [okay]?

25. Ls: Yees

26. T: And particles ze [of] soil which means the particles of soil are bigger than the holes of the what? Of the filter paper, iyavakala [is it clear]?

Excerpt 6: Stage 5 - Teacher B teaches the English scientific terms for the filtration experiment and writes them on the chalkboard - bridging the gap between everyday language and scientific language. 


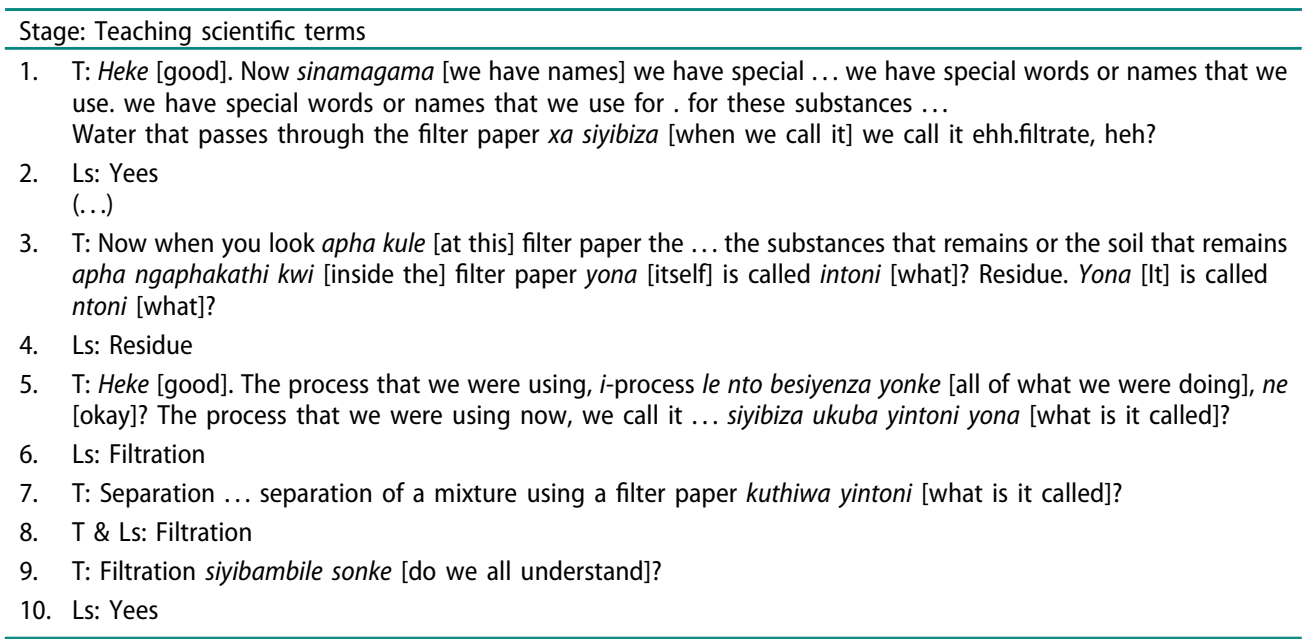

Stage 6: Group discussion on examples of filtration in the home. Teacher B monitored the discussion and engaged with learners - mainly in isiXhosa.

Excerpt 7: Stage 7 - Learners reported back on their discussion and gave examples of making tea and filtering traditional beer. Then, one learner tried to offer an example that puzzled Teacher B until a classmate intervened to help. The interaction followed a dialogic pattern, with Teacher B's responses closely tied to those of the learners', demonstrating 'contingent responsiveness' as described by Wells (1999). Teacher B and the learners mainly used isiXhosa as they worked on meaning in this exploratory talk. The learners were positioned as knowers, and Teacher B helped learners bridge the gap from everyday knowledge to scientific knowledge.

Stage 7: Reporting back

1. L: I pour water in the sand

2. T: Pour water in a sand? Why do you pour water in a sand? (Learners are whispering) Hey hey hey ssh ... masimameleni xa kuthetha omnye umntu [let's listen when someone speaks]. Thetha ke [speak up then].

3. SL: And pour sand in a water

4. T: Khawutsho nge siXhosa [say that in Xhosa].

5. SL: Oh tishara ugalela ama ... [Oh teacher you pour wa...]

6. T: Ho ... uzakuthetha kanjani ufake isandla emlonyeni [Ho ... how are you going to speak with a hand in front of your mouth]?

7. SL: Uxolo tishara, ndigalela amanzi kwi lantuka kumhlaba tishara [sorry teacher, I pour water to soil teacher]

8. T: Xa ubugalela ntoni [what did you pour], Mhmm? Why did you pour sand in water?

9. SL: Uxolo tishara, ndifuna amanzi angcwenge [sorry teacher I want the water to be pure].

10. T: Ufuna angcole [you want it to be dirty]?

11. SL: Angcwenge tishara [to be pure teacher].

12. T: Heh ayivakali le nto uyithethayo! [What you are saying is incomprehensible!].

13. L: (Another learner stands up and explains) - Kaloku ... kaloku ugalela ufuna ukugalela i-cement emanzini mdaka ugqiba angcwenge so ufuna ukuthi abeklini ... ibeklini [because ... because you want ... you pour cement in dirty water and then it clears so you want it to be clean].

14. T: Galela i-cement? [pour cement?]. Ohh pouring i.i.i-cement in dirty water, ne [okay]?

15. Ls: Yees 
(Continued).

Stage 7: Reporting back

16. T: Okay. So what happens? Kwenzeka ntoni kanyekanye apho [what really happens there]? Athini lomanzi usathi ath'angcwenge [what happens to the water you said it clears]? What happens? When you pour that cement what happens?

17. SL: Uxolo tishara xa uwalindile ayangcwenga ... [sorry teacher you wait for it to clear]

18. T: You wait for ...

19. SL: For a few minutes.

20. T: For a few minutes, ne [okay]?

21. Ls: Yees

22. T: Then the water becomes clean?

23. Ls: Yees tishara [teacher].

24. T: What happens to la ... la [that ... that] dirt obabumdaka bebupha [the dirt that was there]?

25. SL: Buhlala ezantsi [it stays in the bottom].

26. T: So that. ehh so that dirt goes down ehh ... to the bottom of the container, ne [okay]?

27. Ls: Yees

28. T: And we use this clean water apha phezulu [that is on top]. So ... so la manzi [that water] when that ... when that ehh dirt moves down, heh? We ... we ... we usually call it landlela yenza ngayo [the way it happens] that method of separation we usually call it $i$-sedimentation. Lo [that] process, the process that they were explaining we usually call it intoni [what]? I-sedmentation, ne [okay]? (writes 'sedimentation' on chalkboard)

29. Ls: Yees

30. T: Obabumdaka bonke buyehla buyohlala phaya ezantsi ... [all that dirt goes down and stays in the bottom...] then usebenzise lendawo iklini apha phezulu [then you use the clean part on top]. lyavakala [is it clear]?

Stage 8: In the final stage of the lesson, learners had to individually draw and label the filtration experiment, moving across the oral - written mode continuum.

\section{Discussion}

It appeared from the analysis of the data that the heteroglossic orientation to multilingualism and pedagogical translanguaging evident in the practice of Teacher B was an important and necessary factor in supporting learners' opportunity to learn science. However, it is also important to note that it appeared that translanguaging on its own was not a sufficient condition but that the learning of science with understanding appeared also to depend on the coherence of the science content in lessons and the engagement of learners in dialogic discourse when working on meaning and constructing science knowledge. In analysing the practice of Teacher B these entangled aspects were artificially teased out and examined to gain a better idea of how they might combine in offering learners a better opportunity to learn science.

\section{Conclusion}

Language and learning in multilingual classrooms in South Africa is a topic much debated, yet still unresolved in classroom practice. As noted, monoglossic orientations to multilingualism in education that originate in the colonial era prevail are resistant to change and mixed messages from education authorities further muddy the waters. The recent research initiatives described in this paper build on a history of research and 
advocacy in favour of heteroglossic orientations and classroom practices that engage with and leverage learners' linguistic capital in the interests of realising greater access, equity and social justice. While these small-scale translanguaging research initiatives open up possibilities, there is need for further development, trialling and consolidation of planned, systematic and sustainable translanguaging pedagogies that can be incorporated into mainstream teacher education.

\section{Notes}

1. The racial classifications that formed the basis of apartheid, including segregation of schools, into those for 'whites', 'Indians', 'coloureds' and 'blacks' are regarded as reprehensible. However the effects of this historic segregation and associated inequalities have far reaching effects on the education system today and so one is obliged to continue to use the racial terminology.

2. 'Townships' are dormitory suburbs that were set-up on the periphery of cities during the apartheid era, to house those Africans who had official permission to work in the cities. As such, they were subject to the apartheid laws of racial segregation and restricted movement. Today some township areas have seen the growth of middle-class enclaves but on the whole, they house the urban poor in a mix of low-cost housing and informal shacks.

3. Mud schools are literally schools made of wattle and daub or mud bricks and as such insecure structures for teaching and learning.

\section{Disclosure statement}

No potential conflict of interest was reported by the author.

\section{Notes on contributor}

Margie Probyn is a researcher at the Centre for Multilingualism and Diversities Research at the University of the Western Cape. Her research interests are language and education in multilingual contexts; language policy and practice; literacy; language and science teaching; teacher education. She has experience in classroom teaching and teacher education.

\section{References}

Adendorff, R. D. 1996. "The Functions of Code Switching among High School Teachers and Students in KwaZulu and Implications for Teacher Education." In Voices from the Language Classroom: Qualitative Research in Second Language Education, edited by K. M. Bailey and D. Nunan, 388-406. Cambridge: Cambridge University Press.

Alexander, N. 2009. "Evolving African Approaches to the Management of Linguistic Diversity: The ACALAN Project." Language Matters 40 (2): 117-132.

Alexander, R. A. 2006. Towards Dialogic Teaching: Rethinking Classroom Talk. 3rd ed. Cambridge: Dialogos.

Baker, C. 2011. Foundations of Bilingual Education and Bilingualism. 5th ed. Bristol: Multilingual Matters.

Barnes, D. [1976] 1992. From Communication to Curriculum. Harmondsworth: Penguin Books.

Bernstein, B. 2000. Pedagogy, Symbolic Control and Identity: Theory, Research, Critique. 2nd ed. Oxford: Rowman \& Littlefield.

Christie, F. 2002. Classroom Discourse Analysis: A Functional Perspective. London: Continuum. 
Creese, and Blackledge. 2010. "Translanguaging in the Bilingual Classroom: A Pedagogy for Learning and Teaching?" The Modern Language Journal 94 (1): 103-115. doi:10.1111/j.15404781.2009.00986.x.

Cummins, J. 1980. "The Construct of Language Proficiency in Bilingual Education." In Georgetown University Round Table on Languages and Linguistics 1980, edited by J. E. Alatis, 81-103. Washington, DC: Georgetown University Press.

Cummins, J. 2008. "Teaching for Transfer: Challenging the Two Solitudes Assumption in Bilingual Education." In Encyclopedia of Language and Education, edited by N. Hornberger, 65-74. New York: Springer.

Department of Basic Education (2013). "The Incremental Introduction of African Languages in South African Schools." https://www.education.gov.za/Portals/0/Documents/Policies/IIAL\% 20Policy\%20September\%202013\%20(3).pdf?ver=2015-03-26-102501-853

Department of Education RSA. (1997) Language in Education Policy [Internet]. Pretoria: Department of Education. http://www.education.gov.za/LinkClick.aspx?fileticket= XpJ7gz4rPT0\%3D

Donovan, M. S., and J. D. Bransford. 2005. "Introduction." In How Students Learn: Science in the Classroom, edited by M. S. Donovan and J. D. Bransford, 1-26. Washington: National Academies Press. http://www.nap.edu/catalog/11102/how-students-learn-science-in-the-classroom

Ferguson, G. 2009. "What Next? Towards an Agenda for Classroom Codeswitching Research." International Journal of Bilingual Education and Bilingualism 12 (2): 231-241. doi:10.1080/ 13670050802153236.

Fleisch, B. 2008. Primary Education in Crisis: Why South African Schoolchildren Underachieve in Reading and Mathematics. Cape Town: Juta.

Fortuin, E. 2017. "Developing the academic literacy of isiXhosa-speaking learners in an Afrikaans-medium school in the Intermediate Phase." Unpublished MEd thesis.,University of the Western Cape.

Garcia, O. 2009. Bilingual Education in the 21st Century: A Global Perspective. Chichester: Wiley-Blackwell.

Garcia, O., and N. Flores. 2012. "Multilingual Pedagogies." In The Routledge Handbook of Multilingualism, edited by M. Martin-Jones, A. Blackledge, and A. Creese, 232-246. London: Routledge.

Gibbons, P. 2006. Bridging Discourses in the ESL Classroom: Students, Teachers and Researchers. London: Continuum.

Guzula, X., C. McKinney, and R. Tyler. 2016. "Languaging-For Learning: Legitimising Translanguaging and Enabling Multimodal Practices in Third Spaces." Southern African Linguistics and Applied Language Studies 34 (3): 211-226. doi:10.2989/16073614.2016.1250360.

Hartshorne, K. 1992. Crisis and Challenge: Black Education 1910-1990. Cape Town: Oxford University Press.

Heugh, K. 1995. "The Multilingual School: Modified Dual Medium." In Multilingual Education for South Africa, edited by K. A. Heugh, A. Siegruhn, and P. Pluddemann, 83-88. Johannesburg: Heinemann.

Heugh, K. 2008. "Language Policy and Education in Southern Africa." In Encyclopedia of Language and Education, 2nd Edition, Volume 1: Language Policy and Political Issues in Education, edited by S. May and N. H. Hornberger, 355-367. New York: Springer.

Heugh, K. 2014. "Multilingualism, the 'African Lingua Franca' and the 'New Linguistic Dispensation'." In Language Rich Africa: Policy Dialogue. The Cape Town Language and Development Conference: Looking beyond 2015, edited by H. Mcllwraith, 80-87. London: British Council.

Howie, S. J. 2001. Mathematics and Science Performance in Grade 8 in South Africa 1998/99: TIMSS-R 1999 South Africa. Pretoria: Human Sciences Research Council.

John, V. (2013, March 8) "Forgotten Schools of the Eastern Cape Left to Rot." Mail and Guardian. http://mg.co.za/article/2013-03-08-00-forgotten-schools-of-the-eastern-cape-left-to-rot

Kane-Berman, J., and L. Holborn, Eds. 2012. South African Survey 2012. Johannesburg: South African Institute of Race Relations.

Krause, L., and M. Prinsloo. 2016. "Translanguaging in a Township Primary School: Policy and Practice." Southern African Linguistics and Applied Language Studies 34 (4): 347-357. doi:10.2989/ 16073614.2016.1261039. 
Lemke, J. L. 1990. Talking Science: Language, Learning and Values. Norwood, New Jersey: Ablex Publishing Corporation.

Lewis, G., B. Jones, and C. Baker. 2012. "Translanguaging: Origins and Development from School to Street and Beyond." Educational Research and Evaluation 18 (7): 641-654. doi:10.1080/ 13803611.2012.718488.

Li, W. 2017. "Translanguaging as a Practical Theory of Language." Applied Linguistics 1-23. doi:10.1093/applin/amx039.

Lin, A. M. Y. 1996. "Bilingualism or Linguistic Segregation? Symbolic Domination, Resistance and Code Switching in Hong Kong Schools." Linguistics and Education 8 (1): 49-84. doi:10.1016/S0898-5898(96) 90006-6.

Lin, A. M. Y. 2012. "Multilingual and Multimodal Resources in Genre-based Pedagogical Approaches to L2 English Content Classrooms." In English-A Changing Medium for Education, edited by C. Leung and B. Street, 79-103. Bristol: Multilingual Matters.

Lin, A. M. Y., and P. Martin. 2005. Decolonisation, Globalisation: Language-In-Education Policy and Practice. Clevedon: Multilingual Mattters.

Macdonald, C. A. 1990. Crossing the Threshold into Standard Three in Black Education: The Consolidated Main Report of the Threshold Project. Pretoria: Human Sciences Research Council.

Makalela, L. 2015. "Translanguaging as a Vehicle for Epistemic Access: Cases for Reading Comprehension and Mutilingual Interactions." Per Linguam 31: 1. doi:10.5785/31-1-628.

Mandela, N. (1997). "Address by President Nelson Mandela at the Education Africa Presidential and Premier Awards." November 22. Accessed 26 July 2019. http://www.mandela.gov.za/mandela_ speeches/1997/971122_educ.htm

Martin, J. R. 1990. "Literacy in Science: Learning to Handle Text as Technology." In Literacy for a Changing World, edited by F. Christie, 79-117. Hawthorn, Vic: Australian Council for Educational Research.

Martin, P. W. 1996. "Code-Switching in the Primary Classroom: One Response to the Planned and Unplanned Language Environment in Brunei." Journal of Multilingual and Multicultural Development 17 (2-4): 128-144. doi:10.1080/01434639608666265.

McDonnell, L. M. 1995. "Opportunity to Learn as a Research Concept and Policy Instrument." Educational Evaluation and Policy Analysis 17 (3): 305-322. doi:10.3102/01623737017003305.

McKinney, C. 2017. Language and Power in Post-Colonial Schooling: Ideologies in Practice. New York: Routledge.

Mehan, H. 1979. Learning Lessons. Cambridge, Mass.: Harvard University Press.

Mercer, N. 1995. The Guided Construction of Knowledge: Talk Amongst Teachers and Learners. Clevedon: Multilingual Matters.

Mercer, N. 2004. "Sociocultural Discourse Analysis: Analysing Classroom Talk as a Social Mode of Thinking." Journal of Applied Linguistics 1 (2): 137-168. doi:10.1558/japl.2004.1.issue-2.

Mortimer, E. F., and P. H. Scott. 2003. Meaning Making in Secondary Science Classrooms. Maidenhead: Open University Press.

Ngcobo, S., N. Ndaba, B. Nyangiwe, N. Mpungose, and R. Jamal. 2016. "Translanguaging as an Approach to Address Language Inequality in South African Higher Education: Summary Writing Skills Development." Critical Studies in Teaching and Learning 4 (2): 10-27.

Plüddemann, P., D. Braam, M. October, and Z. Wababa. 2004. "Dual-Medium and Patallel Medium Schooling in the Western Cape: From Default to Design." PRAESA Occasional Papers No 17. Cape Town: PRAESA: University of Cape Town.

Prinsloo, C., and S. Rogers. 2013. "The Missing Link: Language Skills Crucial to Mathematics and Science." HSRC Review 11 (2): 26-27.

Probyn, M. 2009. "Smuggling the Vernacular into the Classroom: Conflicts and Tensions in Classroom Code-Switching in South Africa." International Journal of Bilingual Education and Bilingualism 12 (2): 123-136. doi:10.1080/13670050802153137.

Probyn, M. 2015. "Pedagogical Translanguaging: Bridging Discourses in South African Science Classrooms." Language and Education 29 (3): 218-234. doi:10.1080/09500782.2014.994525. 
Probyn, M. J. 2001. “Teachers' Voices: Teachers' Reflections on Learning and Teaching through the Medium of English as an Additional Language in South Africa." International Journal for Bilingual Education and Bilingualism 4 (4): 249-266. doi:10.1080/13670050108667731.

Ramani, E., T. Kekana, M. Modiba, and M. Joseph. 2007. "Terminology Development versus Concept Development through Discourse: Insights from a Dual-Medium BA Degree." Southern African Linguistics and Applied Language Studies 25 (2): 207-223. doi:10.2989/16073610709486457.

Reddy, V. 2006. Mathematics and Science Achievementat South African Schools in TIMSS 2003. Cape Town: HSRC Press.

Republic of South Africa. (1996). "The Constitution of the Republic of South Africa. Pretoria: Republic of South Africa; 1996." http://www.gov.za/documents/constitution/1996/a108-96.pdf

Rubagumya, C. 1994. "Introduction." In Teaching and Researching Language in African Classrooms, edited by C. Rubagumya, 1-5. Clevedon: Multilingual Matters.

Setati, M., J. Adler, Y. Reed, and A. Bapoo. 2002. "Code-Switching and Other Language Practices in Mathematics, Science and English Language Classrooms in South Africa." In Challenges of Teacher Development: An Investigation of Take-Up in South Africa, edited by J. Adler and Y. Reed, 72-93. Pretoria: Van Schaik Publishers.

Soudien, C. 2004. "'Constituting the Class': An Analysis of the Process of 'Integration' in South African Schools." In Changing Class: Education and Social Change in Post-Apartheid South Africa, edited by L. Chisholm, 89-114. Cape Town: HSRC Press.

Statistics South Africa. 2012. Census 2011: Census in Brief. Pretoria: Author.

Van der Berg, S. 2006. "How Effective are Poor Schools? Poverty and Educational Outcomes in South Africa." Stellenbosch Economic Working Papers: 06/06. Stellenbosch: Stellenbosch University/ Bureau for Economic Research.

Wells, G. 1999. Dialogic Inquiry: Towards a Sociocultural Practice and Theory of Education. Cambridge: Cambridge University Press. 